JMI Vol. 43 No. 2, Desember 2021

METAL INDONESIA

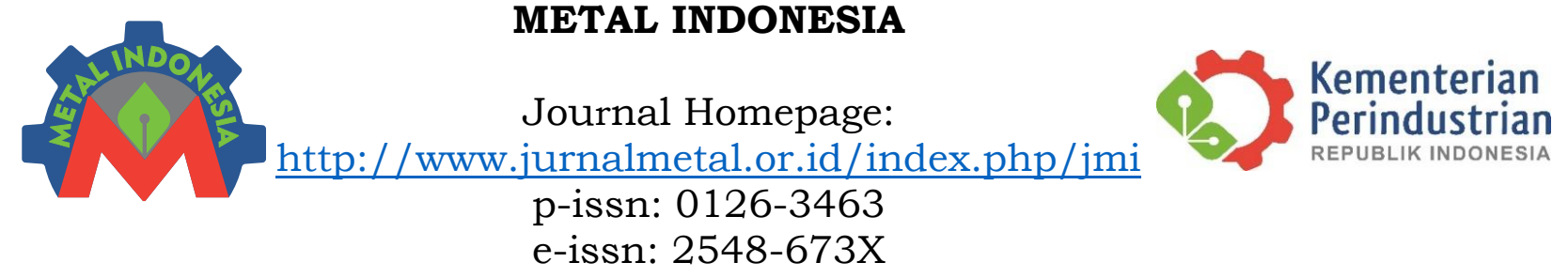

\title{
PENGARUH INHIBITOR EKSTRAK DAUN JAMBU BIJI (PSIDIUM GUAJAVA) PADA LAJU KOROSI PIPA GALVANIS
}

\section{THE EFFECT OF GUAJAVA LEAF EXTRACT INHIBITORS ON CORROSION RATE OF GALVANIZED PIPE}

\author{
Kurnia Hastuti', Rieza Zulrian Aldio",1, Yuda Nugroho' ${ }^{1}$ \\ ${ }^{1}$ Program Studi Teknik Mesin, Fakultas Teknik, Universitas Islam Riau \\ Jl. Kaharuddin Nasution No. 133 Perhentian Marpoyan, Pekanbaru \\ E-mail : rieza@eng.uir.ac.id
}

\begin{abstract}
Abstrak
PT Sekarbumi Alamlestari merupakan pabrik kelapa sawit yang menggunakan pipa galvanis dalam proses pendistribusian air bersih yang digunakan untuk proses produksi dan penggunaan pada perumahan karyawan perusahaan. Pipa galvanis dapat terkorosi bila terlalu lama berada di lingkungan air gambut, karena air gambut bersifat sangat asam dan korosif. Korosi ini akan berdampak negatif pada kualitas dan proses distribusi air bersih tersebut. Salah satu cara untuk mengurangi korosi yaitu dengan penambahan inhibitor korosi. Jambu biji merupakan salah satu jenis tumbuhan yang dapat digunakan sebagai inhibitor korosi karena mengandung tanin pada daunnya. Penelitian ini bertujuan untuk mengetahui pengaruh ekstrak daun jambu biji pada laju korosi pipa galvanis. Metode pengukuran laju korosi yang digunakan adalah metode kehilangan berat selama perendaman. Spesimen pipa galvanis direndam di dalam medium air gambut dengan penambahan dan tanpa penambahan inhibitor. Inhibitor yang diberikan divariasikan yaitu $5 \%, 7 \%, 9 \%, 11 \%$ dan lama waktu perendaman yang diberikan yaitu selama 42 hari. Hasil penelitian menunjukkan ekstrak daun jambu biji efektif dalam mengurangi laju korosi. Pada perendaman tanpa menggunakan pompa laju korosi terendahnya didapat pada konsentrasi inhibitor $9 \%$ yaitu sebesar 0,018 $\mathrm{mm} / \mathrm{y}$, dan pada perendaman menggunakan pompa laju korosi terendahnya didapat pada konsentrasi inhibitor $11 \%$ yaitu sebesar $0,019 \mathrm{~mm} / \mathrm{y}$.
\end{abstract}

Kata Kunci: Air gambut, ekstrak daun jambu biji, korosi, pipa galvanis, tannin

\section{Abstract}

Sekarbumi Alamlestari is a palm oil mill that uses galvanized pipes in the process of distributing clean water for the production process and employee housing. Galvanized pipe will corrode if exposed too long in a peat water environment, since it is very acid and corrosive. The corrosion will give negative impact on the quality and distribution process of the clean water. The addition of a corrosion inhibitor is one of many ways to reduce corrosion rate. Guava is a type of plant that can be used as a corrosion inhibitor because it contains tannins in its leaves. This study aims to determine the effect of guava leaf extract as an inhibitor. The method of measuring the corrosion rate is by the weight loss calculation during the soaking process. The specimens soaked in peat water with and without the addition of inhibitors. The inhibitors are varied at 5\%,7\%, 9\% and $11 \%$ with soaking time at 42 days. The results showed that guava leaf extract 
was effective in reducing the corrosion rate. During the soaking without using pump, the lowest corrosion rate obtained at $9 \%$ inhibitor concentration is $0.018 \mathrm{~mm} / y$, and while using a pump, concentration at $11 \%$ is $0.019 \mathrm{~mm} / \mathrm{y}$.

Keywords : Peat water, guava leaf extract, corrosion, galvanized pipe, tannins

\section{PENDAHULUAN}

Dalam perkembangan dunia teknologi dan industri, logam merupakan salah satu bahan utama yang sangat besar peranannya. Salah satu karakteristik logam yang paling rentan terjadi dan mengganggu kinerja logam adalah korosi. Meski logam memiliki lapisan pelindung, korosi tetap akan terjadi apabila logam terekspos terlalu lama oleh asam atau medium yang mengandung klorida. Secara definisi korosi merupakan serangkaian proses degradasi masa atau mutu suatu material (biasanya logam) akibat interaksi alamiah atau buatan terhadap lingkungan (Mulyati, 2020). Salah satu media yang bersifat korosif adalah air gambut. Hampir 10 persen wilayah Indonesia sendiri dipenuhi oleh lahan gambut (Anggriawan et al., 2015)

Pada pabrik kelapa sawit, korosi sering terjadi pada pipa penyuplai air bersih yang menggunakan pipa galvanis. Pipa galvanis merupakan pipa yang sudah dilapisi seng dan lapisan seng inilah yang melindungi pipa dari korosi. Namun kondisi lingkungan yang bervariasi tetap dapat menyebabkan korosi pada logam yang dilapisi seng. Pada perusahaan kelapa sawit air yang digunakan untuk keperluan produksi dan yang akan disalurkan ke perumahan karyawan pada awalnya merupakan air gambut yang selanjutnya akan diproses sehingga menjadi air bersih yang dapat digunakan untuk proses produksi dan disalurkan ke perumahan karyawan perusahaan. Beberapa langkah pencegahan korosi yang biasa dilakukan adalah dengan menggunakan inhibitor, pigmen dan coating (Irianty \& Khairat, 2013)(Anyiam et al., 2020)

(Cholil et al., 2018) melakukan penelitian mengenai pengaruh penambahan inhibitor korosi pada baja lunak dalam media air gambut. Baja lunak direndam selama 1,3 dan 5 hari dan hasilnya baja lunak yang tidak dilapisi dengan inhibitor laju korosinya lebih tinggi dibandingkan dengan yang dilapisi dengan inhibitor korosi. Penelitian ini membuktikan bahwa air gambut dapat menyebabkan korosi pada baja. Namun korosi pada baja dapat dikurangi dengan beberapa cara dan salah satu cara untuk mengurangi laju korosi pada baja adalah dengan menggunakan inhibitor.

Inhibitor korosi adalah suatu zat yang bila ditambahkan dalam konsentrasi kecil dapat mengurangi kecepatan reaksi antara media korosif dengan logam yang bisa menyebabkan korosi pada logam tersebut. Inhibitor korosi terbagi menjadi dua yaitu inhibitor anorganik dan inhibitor organik. Inhibitor anorganik antara lain silikat, borat, tungstat, fosfat, kromat, dikromat, dan arsenat merupakan jenis bahan kimia yang berbahaya, mahal dan tidak ramah lingkungan (Amalia, 2016). Inhibitor organik merupakan inhibitor korosi yang terbuat dari bahan-bahan alami yang banyak tersedia di alam. Inhibitor organik selain dapat digunakan sebagai penghambat laju korosi, inhibitor organik juga memiliki sifat non-toksik, murah, mudah didapat dan dapat diperbaharui. Salah satu inhibitor organik adalah inhibitor yang terbuat dari ekstrak daun jambu biji.

Jambu biji (psidium guajava) merupakan tanaman yang tumbuh subur di Indonesia, hampir setiap daerah di Indonesia dapat dijumpai tanaman jambu biji. Salah satu daerah yang banyak dijumpai tanaman jambu biji adalah daerah Kampar Riau. Masyarakat Kampar Riau banyak membudidayakan tanaman jambu biji ini untuk dimanfaatkan buahnya dan juga sebagai tanaman hias di lingkungan rumah, tetapi masyarakat tidak mengetahui bahwa daun dari jambu biji ini bisa dimanfaatkan sebagai inhibitor korosi. Penggunaan inhibitor korosi menjadi metode yang efektif untuk menahan laju korosi (Wahyuni \& Ab, 2014) Daun jambu biji mengandung antioksidan dan tanin, kandungan tanin tersebut yang dapat dimanfaatkan sebagai zat anti korosi menggantikan fungsi dari kromat dan timbal merah dalam zat dasar.

Penelitian sebelumnya (Tambun et al., 2015) tentang kemampuan daun jambu biji sebagai inhibitor korosi besi pada medium asam klorida. Plat besi direndam dalam 50mL larutan $\mathrm{HCl}$ selama 3,6,9 dan 12 hari. Dan didapatkan 
hasil bahwa dengan penambahan inhibitor tanin daun jambu biji laju korosi plat besi semakin berkurang. Laju korosi terendah masing-masing didapat pada penambahan inhibitor $9 \mathrm{~g}$ dan lama perendaman selama 12 hari.

Penelitian ini bertujuan untuk mengetahui laju korosi yang terjadi pada pipa galvanis oleh air gambut. Melalui penelitian ini, pengaruh penambahan dan jumlah penambahan inhibitor alami tersebut terhadap laju korosi pada pipa galvanis dapat diketahui. Penelitian ini terfokus pada satu jenis inhibitor, yaitu inhibitor jambu biji.

\section{METODOLOGI}

\section{Waktu dan Tempat Penelitian}

Pada penelitian ini memiliki beberapa tahapan yang dimulai dengan pemotongan material, penyediaan media korosif sampai dengan pengambilan data. Keseluruhan dari penelitian ini dilaksanakan kurang lebih selama 3 bulan dari Februari hingga Mei, dengan lama perendaman selama 42 hari. Perendaman dilakukan lebih lama karena lama perendaman akan meningkatkan efisiensi inhibisi (Tambun et al. 2015). Kemudian nilai kehilangan berat akan dihitung untuk mencari laju korosi pada spesimen. Untuk proses pengambilan data dilaksanakan di Laboratorium Teknik Mesin Universitas Islam Riau dan Laboratorium Kimia Organik Bahan Alam Universitas Riau.

\section{Alat dan Bahan}

Bahan yang digunakan adalah sebagai berikut: daun jambu biji, pipa, galvanis, etanol $70 \%$, air gambut dan akuades.

\section{Persiapan Spesimen}

Spesimen yang digunakan pada penelitian ini adalah pipa galvanis dengan diameter $1 \frac{1 / 2}{2}$ inci dan tebal $2 \mathrm{~mm}$. Pipa dipotong sepanjang $40 \mathrm{~mm}$ lalu dibelah menjadi 2 bagian dan spesimen yang digunakan sebanyak 10 buah.

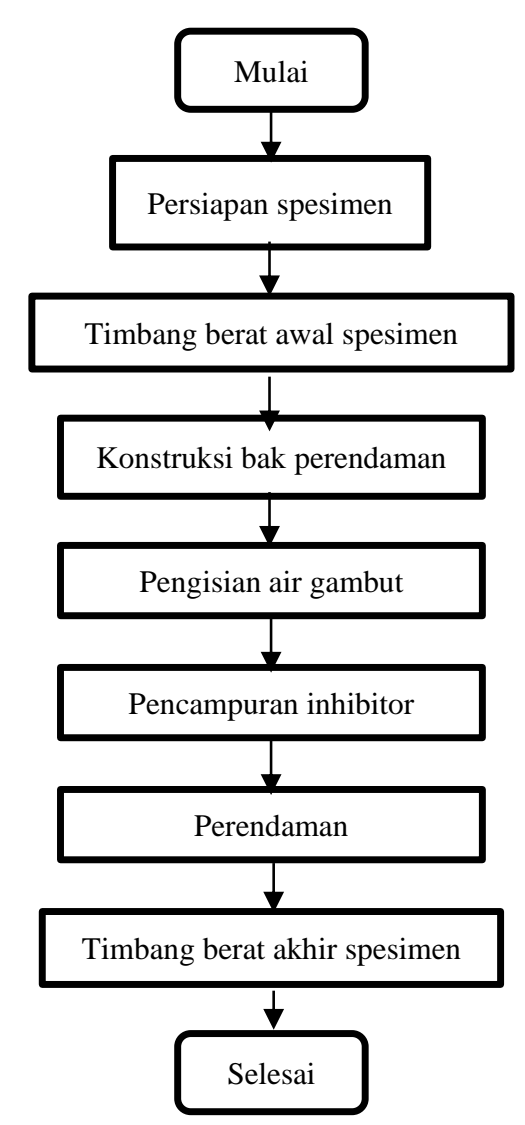

Gambar 1. Flowchart penelitian

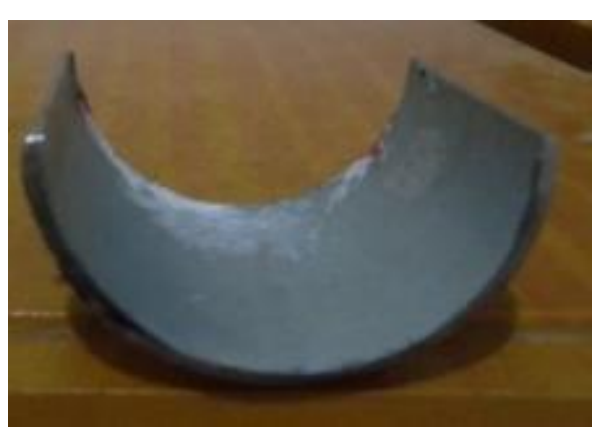

Gambar 2. Spesimen uji

Sampel dicelupkan ke dalam larutan akuades untuk membersihkan spesimen.

\section{Pembuatan Bak Pengujian}

Bak pengujian korosi yang digunakan terbuat dari material kaca dengan ukuran 40x34x15 cm dan akan ditambahkan pompa akuarium untuk membuat efek aliran pada saat pengujian. 


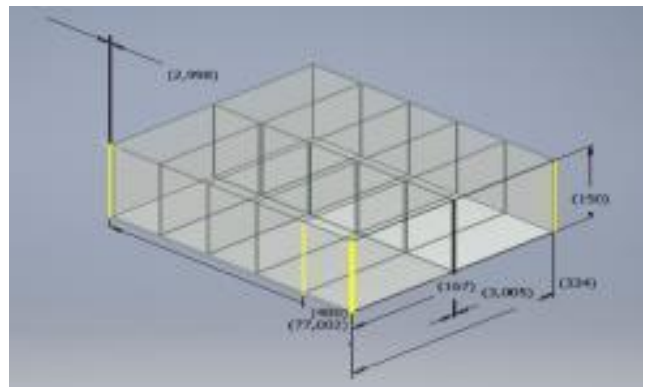

Gambar 3. Sketsa bak Pengujian

\section{Persiapan Inhibitor}

Pada pengujian ini inhibitor yang digunakan adalah inhibitor yang terbuat dari ekstrak daun jambu biji (Psidium guava). Daun jambu biji yang digunakan dalam penelitian ini diperoleh dari lingkungan perumahan karyawan PT. Sekarbumi Alamlestari. Berikut merupakan langkah pembuatan serbuk daun jambu biji. Untuk membuat inhibitor tersebut maka perlu dilakukan beberapa persiapan sebagai berikut.

$>$ Persiapkan daun jambu biji yang masih segar sebanyak $2 \mathrm{~kg}$ dan kemudian dicuci hingga bersih.

$>$ Pisahkan daun jambu biji dengan tulang daunnya.

$>$ Berikutnya daun jambu biji dikeringkan dengan udara (tidak terkena matahari secara langsung) selama 3 hari.

$>$ Daun jambu biji yang sudah dikeringkan selanjutnya di blender untuk mendapatkan serbuk daun jambu biji.

$>$ Kemudian melakukan ekstraksi dengan metode maserasi dengan memasukkan serbuk daun jambu biji yang telah halus ke dalam wadah baskom yang telah berisi etanol $70 \%$ selama 2 hari.

$>$ Hasil perendaman kemudian disaring menggunakan kertas saring sehingga diperoleh filtrat.

$>$ Filtrat kemudian diuapkan menggunakan mesin rotary evaporator dengan kecepatan $200 \mathrm{rpm}$ dan suhu $70^{\circ} \mathrm{C}$ hingga menghasilkan ekstrak pekat (Ali et al., 2014).

\section{HASIL DAN PEMBAHASAN}

Penelitian yang dilakukan bertujuan untuk mengetahui laju korosi dan pemakaian inhibitor pada pipa jenis galvanis di larutan air gambut. Beberapa pengujian telah dilakukan dan data hasil penelitian tersebut adalah sebagai berikut:

a. Pengujian Tingkat Keasaman Air Gambut

Berdasarkan hasil pengecekan menggunakan kertas universal Indicator maka didapat tingkat keasaman $(\mathrm{PH})$ dari air gambut yaitu kisaran 4 sampai 5. Seperti yang terlihat pada Gambar 4.

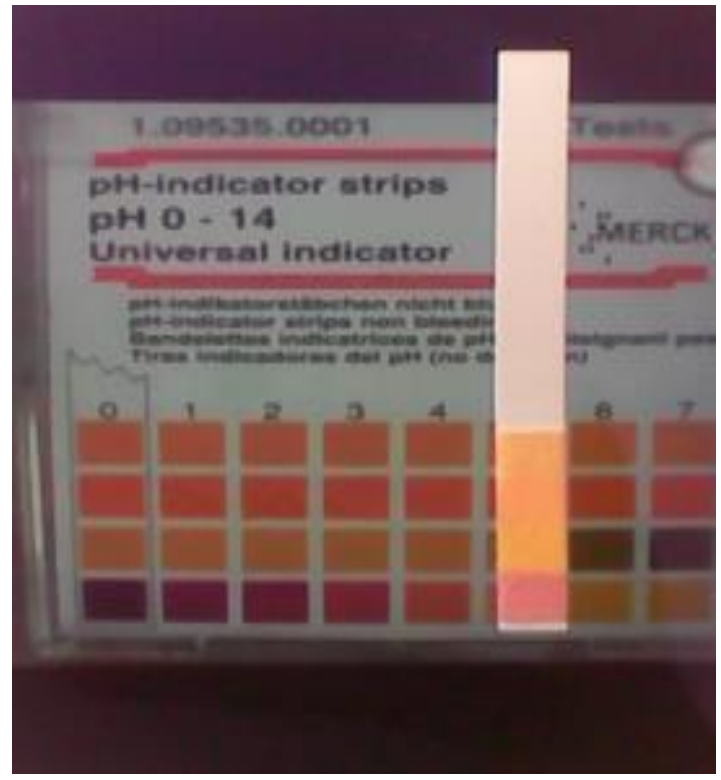

Gambar 4. Hasil Pengukuran Ph Air Gambut Menggunakan Universal Indicator

Warna merah kecokelatan dan rendahnya $\mathrm{Ph}$ dari air gambut di sebabkan oleh tingginya kandungan zat organik (bahan humus) yang terlarut dalam bentuk asam humus dan turunannya. Asam humus berasal dari dekomposisi bahan-bahan organik seperti kayu, daun, pohon dengan berbagai tingkat dekomposisi. Tetapi secara umum asam humus dalam air gambut telah mencapai dekomposisi yang stabil. PH rendah pada air gambut menandakan air gambut bersifat asam, sehingga air gambut bersifat korosif.

a. Hasil Pengujian Tanin Pada Ekstrak Daun Jambu Biji

Pada penelitian ini filtrat hasil ekstraksi ditambah beberapa tetes $\mathrm{FeCl}_{3}$. Hasil ekstraksi 
berwarna hitam kehijauan yang artinya positif mengandung tanin atau ekstrak ditambahkan dengan larutan galatin dan hasilnya terbentuk endapan putih atau kekuningan yang artinya positif mengandung tanin. Seperti yang terlihat pada Gambar 5.

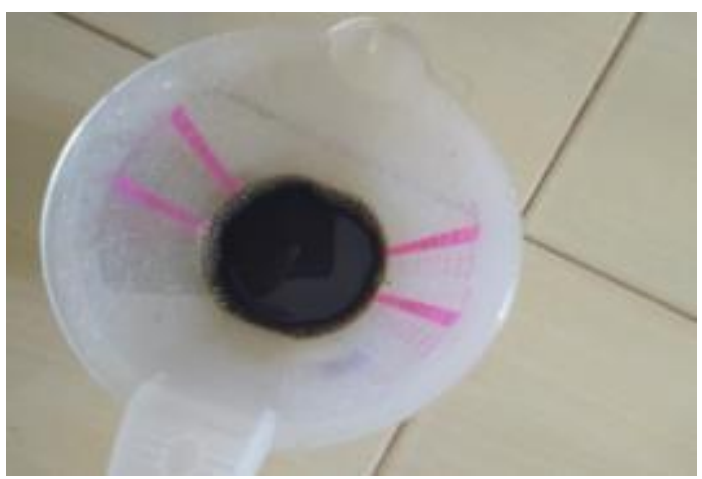

Gambar 5a. Pengujian Tanin

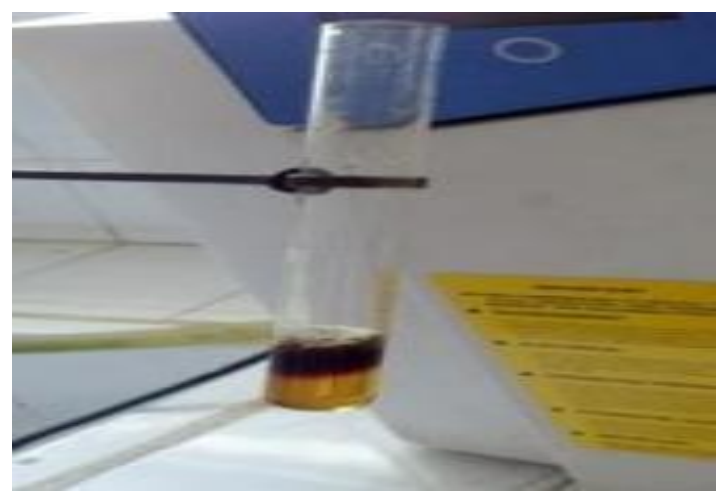

Gambar 5b. Pengujian Tanin

Tabel 1. Berat Awal Spesimen Sebelum Perendaman

\begin{tabular}{|c|c|c|c|c|}
\hline No & Kelompok & Inhibitor & Wo (gram) & $\begin{array}{c}\text { Waktu } \\
\text { perendaman }\end{array}$ \\
\hline 1 & \multirow{5}{*}{ Tanpa pompa } & $0 \%$ & 21,547 & 42 hari \\
\hline 2 & & $5 \%$ & 20,682 & 42 hari \\
\hline 3 & & $7 \%$ & 22,475 & 42 hari \\
\hline 4 & & $9 \%$ & 21,526 & 42 hari \\
\hline 5 & & $11 \%$ & 21,541 & 42 hari \\
\hline 1 & \multirow{5}{*}{$\begin{array}{c}\text { Menggunakan } \\
\text { pompa }\end{array}$} & $0 \%$ & 22,726 & 42 hari \\
\hline 2 & & $5 \%$ & 22,715 & 42 hari \\
\hline 3 & & $7 \%$ & 21,684 & 42 hari \\
\hline 4 & & $9 \%$ & 20,975 & 42 hari \\
\hline 5 & & $11 \%$ & 21,817 & 42 hari \\
\hline
\end{tabular}

b. Hasil Pengujian Berat Awal Spesimen

Sebelum melakukan proses perendaman, spesimen ditimbang untuk mengetahui berat awalnya. Berat awal spesimen diberikan pada Tabel 1
Kehilangan berat spesimen didapat dari selisih berat akhir setelah perendaman selama waktu 42 hari.

Hasil kehilangan berat spesimen didapat menggunakan rumus : $\Delta W=W 0-W 2$.

c. Hasil Pengujian Kehilangan Berat Setelah

Dilakukan Perendaman. 
Tabel 2. Kehilangan Berat Spesimen Setelah Dilakukan Perendaman

\begin{tabular}{|c|c|c|c|c|c|c|}
\hline No & Kelompok & Inhibitor & $\begin{array}{c}\text { Wo } \\
\text { (gram) }\end{array}$ & $\begin{array}{c}\text { W2 } \\
\text { (gram) }\end{array}$ & $\begin{array}{c}\text { Kehilangan } \\
\text { berat (gram) }\end{array}$ & $\begin{array}{c}\text { Waktu } \\
\text { perendaman }\end{array}$ \\
\hline 1 & \multirow{5}{*}{ Tanpa pompa } & $0 \%$ & 21,547 & 21,39 & 0,157 & 42 hari \\
\hline 2 & & $5 \%$ & 20,682 & 20,36 & 0,146 & 42 hari \\
\hline 3 & & $7 \%$ & 22,475 & 22,35 & 0,125 & 42 hari \\
\hline 4 & & $9 \%$ & 21,526 & 21,437 & 0,089 & 42 hari \\
\hline 5 & & $11 \%$ & 21,541 & 21,434 & 0,107 & 42 hari \\
\hline 1 & \multirow{5}{*}{$\begin{array}{c}\text { Menggunaka } \\
\text { n pompa }\end{array}$} & $0 \%$ & 22,726 & 22,534 & 0,192 & 42 hari \\
\hline 2 & & $5 \%$ & 22,715 & 22,532 & 0,183 & 42 hari \\
\hline 3 & & $7 \%$ & 21,684 & 21,516 & 0,168 & 42 hari \\
\hline 4 & & $9 \%$ & 20,975 & 20,858 & 0,117 & 42 hari \\
\hline 5 & & $11 \%$ & 21,914 & 21,817 & 0,097 & 42 hari \\
\hline
\end{tabular}

Dari hasil penimbangan spesimen setelah perendaman menunjukkan bahwa konsentrasi inhibitor dan penggunaan pompa mempengaruhi proses korosi. Seperti terlihat pada tabel 2 yang menunjukkan bahwa konsentrasi inhibitor dan penggunaan pompa mempengaruhi kehilangan berat spesimen selama perendaman.

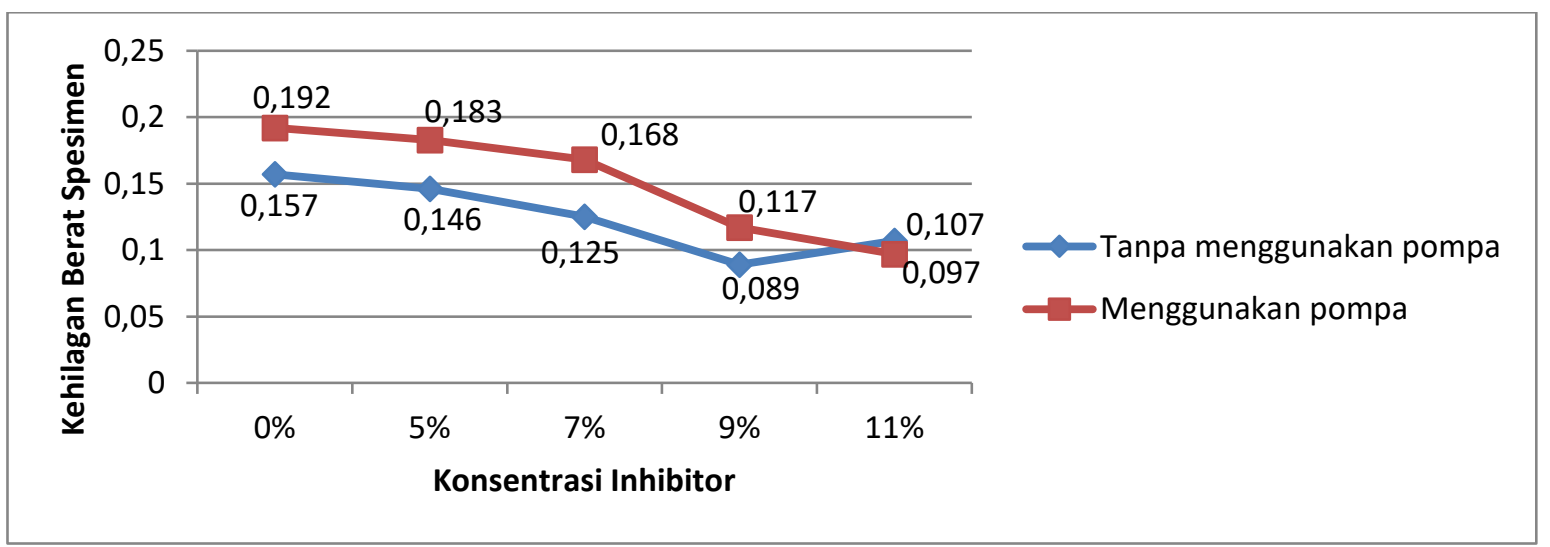

Gambar 6. Grafik Hubungan Konsentrasi Inhibitor dan Penggunaan Pompa Dalam Larutan Air Gambut Terhadap Kehilangan Berat.

Gambar 6 menunjukkan bahwa peningkatan konsentrasi inhibitor dari 5\%, 7\%, $9 \%$, dan $11 \%$ mengakibatkan penurunan kehilangan berat material pada penelitian yang menggunakan pompa, sedangkan pada penelitian yang tidak menggunakan pompa kehilangan berat menurun pada konsentrasi inhibitor 5\%, 7\%, 9\% tetapi pada konsentrasi $11 \%$ kehilangan berat kembali naik.

d. Hasil Pengujian laju korosi

Perhitungan laju korosi yang dapat dinyatakan dalam rumus sebagai berikut:

$$
\mathrm{CR}=\frac{K \cdot W}{\text { A.t.p }}
$$


Dimana:

$$
\begin{aligned}
\mathrm{CR} & =\text { Laju korosi }(\mathrm{mm} / \mathrm{y}) \\
\mathrm{K} & =\text { Konstanta laju korosi }\left(8.76 \times 10^{4}\right) \mathrm{W} \\
& =\text { Kehilangan berat }(\mathrm{gram}) \\
\mathrm{t} & =\text { Waktu perendaman }(\mathrm{jam}) \\
\mathrm{A} & =\text { Luas permukaan }(\mathrm{cm} 2) \\
\mathrm{p} & =\text { Massa jenis }\left(\mathrm{gram} / \mathrm{cm}^{2}\right)
\end{aligned}
$$

Dimana bentuk dari spesimen dapat dilihat pada Gambar 4.3 dengan ukuran yang sudah ditentukan.

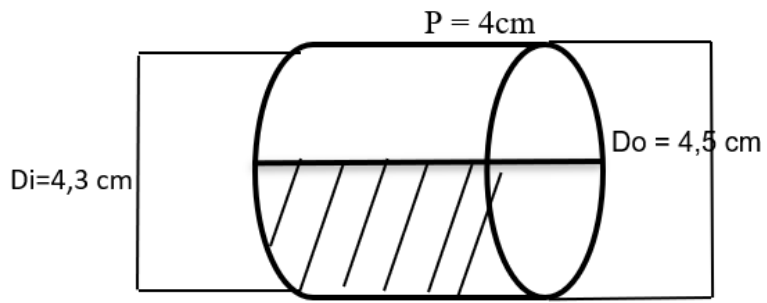

Gambar 7. Sketsa material uji

\begin{tabular}{|c|c|c|c|c|c|}
\hline No & Kelompok & Inhibitor & $\begin{array}{c}\text { Kehilangan } \\
\text { berat (gram) }\end{array}$ & Laju Korosi $(\mathrm{mm} / \mathrm{y})$ & $\begin{array}{c}\text { Waktu } \\
\text { perendaman }\end{array}$ \\
\hline 1 & \multirow{5}{*}{ Tanpa pompa } & $0 \%$ & 0,157 & 0,031 & 42 hari \\
\hline 2 & & $5 \%$ & 0,146 & 0,029 & 42 hari \\
\hline 3 & & $7 \%$ & 0,125 & 0,025 & 42 hari \\
\hline 4 & & $9 \%$ & 0,089 & 0,018 & 42 hari \\
\hline 5 & & $11 \%$ & 0,107 & 0,021 & 42 hari \\
\hline 1 & \multirow{5}{*}{$\begin{array}{l}\text { Menggunakan } \\
\text { pompa }\end{array}$} & $0 \%$ & 0,192 & 0,038 & 42 hari \\
\hline 2 & & $5 \%$ & 0,183 & 0,036 & 42 hari \\
\hline 3 & & $7 \%$ & 0,168 & 0,033 & 42 hari \\
\hline 4 & & $9 \%$ & 0,117 & 0,023 & 42 hari \\
\hline 5 & & $11 \%$ & 0,097 & 0,019 & 42 hari \\
\hline
\end{tabular}

Dari hasil perhitungan laju korosi maka didapat nilai laju korosi dari masing-masing spesimen. Hasil perhitungan laju korosi ditampilkan pada Tabel 3.

Tabel 3. Nilai Laju Korosi Pada setiap Spesimen Uji

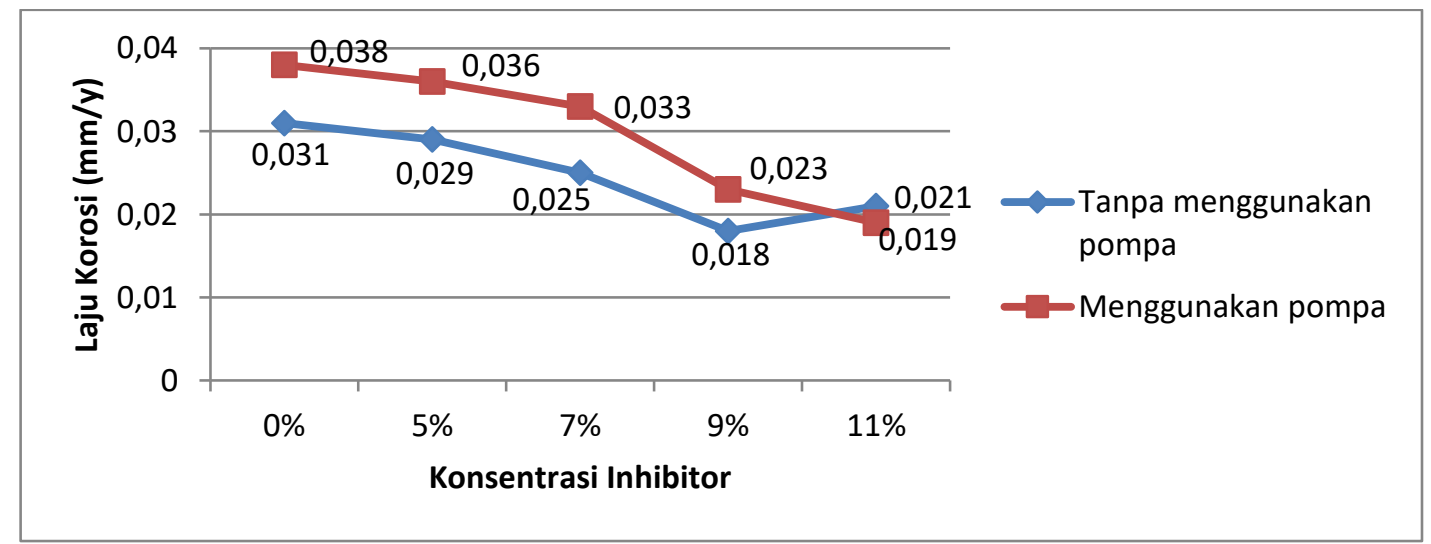

Gambar 8. Grafik Hubungan Antara Konsentrasi Inhibitor Dan penggunaan Pompa Terhadap Laju korosi 
Tabel 3 menunjukkan penggunaan pompa dan konsentrasi inhibitor mempengaruhi laju korosi pada spesimen. Hal ini dapat dilihat lebih jelas pada gambar 7 di bawah ini.

Gambar 8 menunjukkan bahwa perendaman dengan menggunakan pompa laju korosinya relatif turun dan penurunan laju korosi maksimum terjadi pada konsentrasi inhibitor $11 \%$ yaitu $0.019 \mathrm{~mm} / \mathrm{y}$. Sedangkan pada perendaman spesimen yang tanpa menggunakan pompa penurunan laju korosi terendah terjadi pada konsentrasi inhibitor $9 \%$ yaitu $0.018 \mathrm{~mm} / \mathrm{y}$ namun pada penambahan inhibitor $11 \%$ korosinya kembali naik, hal ini dikarenakan pada perendaman tanpa pompa pengendapan inhibitor terjadi lebih cepat karena fluidanya tidak bergerak dari pada perendaman yang menggunakan pompa yang fluidanya bergerak, akibatnya inhibitor lebih cepat ter absorpsi dan membentuk lapisan tipis pada permukaan baja yang berfungsi menghambat serangan korosi terhadap logamnya.
Semakin lamanya perendaman dan banyaknya jumlah inhibitor yang diberikan akan menurunkan laju korosi, namun pada suatu titik tertentu dimana absorpsi telah mencapai titik jenuh, sehingga laju korosinya cenderung konstan bahkan akan naik.

e. Hasil Pengujian Efisiensi Inhibitor

Hasil perhitungan efisiensi inhibitor didapat dengan menggunakan rumus di bawah ini:

$$
\text { Efisiensi inhibitor }=\frac{C R o-C R i n h}{C R o} \times 100 \% \ldots . .(1)
$$

Dimana :

$$
\begin{array}{ll}
\text { CRo } & =\text { Laju korosi tanpa inhibitor } \\
\text { CRinh } & =\text { laju korosi dengan inhibitor }
\end{array}
$$

Dari hasil perhitungan nilai efisiensi

\begin{tabular}{|c|c|c|c|c|}
\hline No & Kelompok & Inhibitor & $\begin{array}{c}\text { Efisiensi inhibitor } \\
\%\end{array}$ & Waktu perendaman \\
\hline 1 & \multirow{5}{*}{$\begin{array}{l}\text { Tanpa } \\
\text { pompa }\end{array}$} & $0 \%$ & $0 \%$ & 42 hari \\
\hline 2 & & $5 \%$ & $6,5 \%$ & 42 hari \\
\hline 3 & & $7 \%$ & $19 \%$ & 42 hari \\
\hline 4 & & $9 \%$ & $42 \%$ & 42 hari \\
\hline 5 & & $11 \%$ & $32 \%$ & 42 hari \\
\hline 1 & \multirow{5}{*}{$\begin{array}{l}\text { Menggunaka } \\
\text { n pompa }\end{array}$} & $0 \%$ & $0 \%$ & 42 hari \\
\hline 2 & & $5 \%$ & $5.2 \%$ & 42 hari \\
\hline 3 & & $7 \%$ & $13 \%$ & 42 hari \\
\hline 4 & & $9 \%$ & $39,5 \%$ & 42 hari \\
\hline 5 & & $11 \%$ & $50 \%$ & 42 hari \\
\hline
\end{tabular}
inhibitor maka diperoleh data sebagai berikut:

Tabel 4. Nilai Efisiensi Inhibitor Pada Setiap Spesimen Uji.

Tabel 4 menunjukkan konsentrasi inhibitor dan penambahan pompa mempengaruhi efisiensi inhibitor. Nilai efisiensi tertinggi diperoleh pada perendaman menggunakan pompa dengan konsentrasi inhibitor $11 \%$ yaitu efisiensinya sebesar 50\%. Hal ini terlihat lebih jelas seperti Gambar 9. 


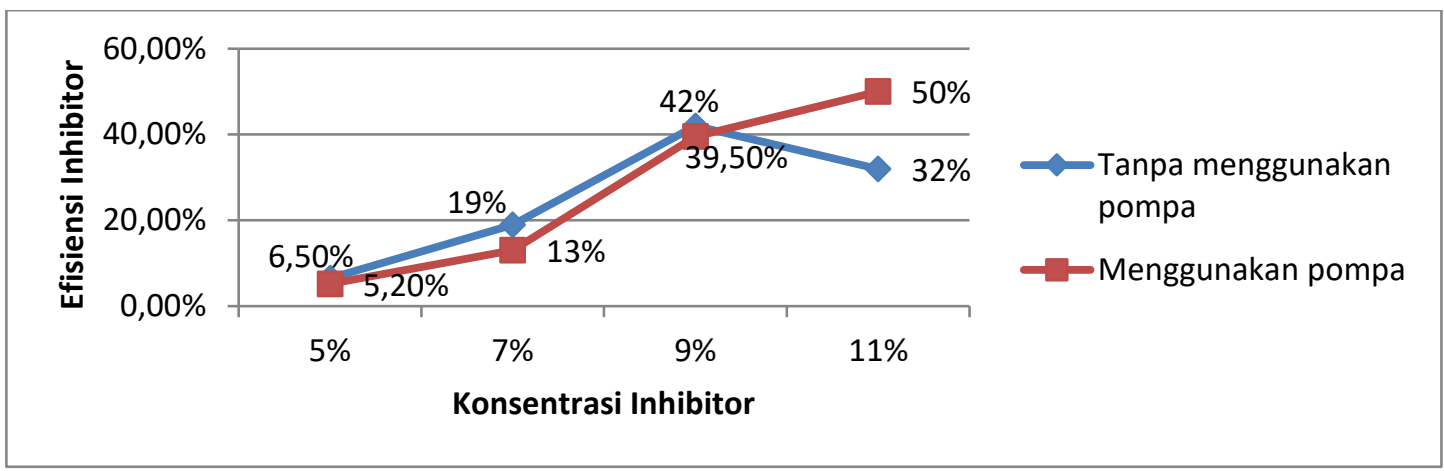

Gambar 9. Grafik Hubungan Antara konsentrasi Inhibitor Dan Penambahan Pompa Terhadap Nilai Efisiensi Inhibitor

Nilai efisiensi inhibitor terbesar didapat pada perendaman material yang menggunakan pompa dengan konsentrasi inhibitornya $11 \%$ yaitu didapat nilai efisiensinya sebesar $50 \%$. Sedangkan nilai efisiensi inhibitor terendah didapat pada perendaman material yang menggunakan pompa pula dengan konsentrasi inhibitornya $5 \%$ yaitu didapat nilai efisiensinya sebesar 5,4\%. Pada perendaman yang tidak menggunakan pompa nilai efisiensi terbesar yaitu sebesar $42 \%$ pada perendaman menggunakan konsentrasi inhibitor $9 \%$ dan kemudian menurun menjadi $32 \%$ pada perendaman menggunakan konsentrasi inhibitor $11 \%$ hal ini diakibatkan karena proses inhibitor telah mengalami kejenuhan sehingga pada konsentrasi ini tidak dapat meningkatkan efisiensi dari inhibitor.

\section{f. Hasil Uji Metalografi}

Jika logam dimasukkan ke dalam larutan elektrolit maka logam akan terlarut sambil melepaskan elektron. Akibatnya terjadi korosi pada permukaan logam yang anodik. Perbedaan potensial ini dikarenakan komposisi kimia yang tidak sama pada masing-masing butir kristal atau perbedaan fase pada permukaan logam yang kontak dengan elektrolit.

Untuk melihat struktur permukaan logam akibat serangan dari korosi beserta penambahan inhibitor ekstrak daun jambu biji dengan lama waktu perendaman 42 hari dapat dilakukan uji metalografi menggunakan mikroskop optik dengan pembesaran $5 \mathrm{x}$ didapat hasil seperti Gambar 10 dan 11.

Berdasarkan Gambar 10 dan 11, terlihat adanya perbedaan antara spesimen yang tidak terendam di air gambut dan dengan spesimen yang direndam dengan air gambut, terlihat spesimen yang terendam di air gambut banyak terjadi korosi. Tetapi spesimen yang terendam di air gambut dan dengan ditambahkan inhibitor ekstrak daun jambu biji terlihat korosinya semakin berkurang seiring bertambahnya jumlah inhibitor. Warna hitam pada gambar merupakan produk korosi yang terjadi pada spesimen semakin gelap gambarnya maka semakin tebal korosi yang terjadi pada spesimen. 


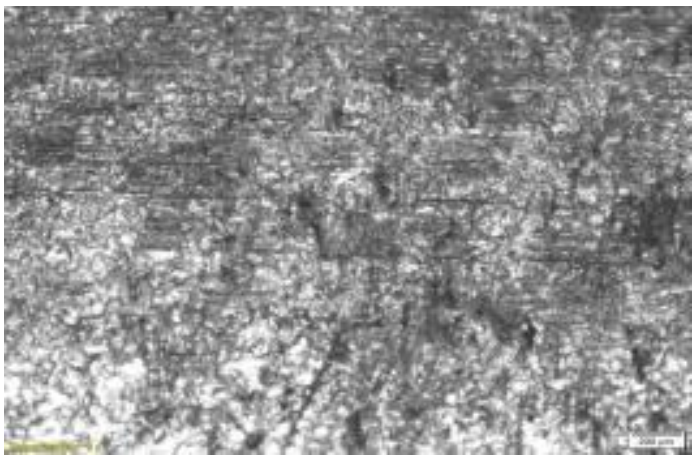

a. Sebelum perendaman

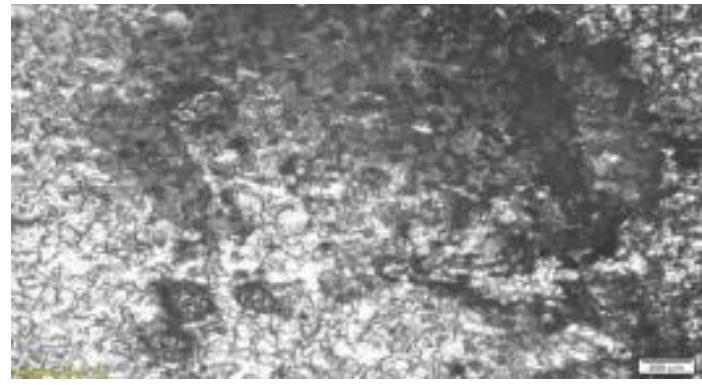

c. Perendaman dengan inhibitor $5 \%$

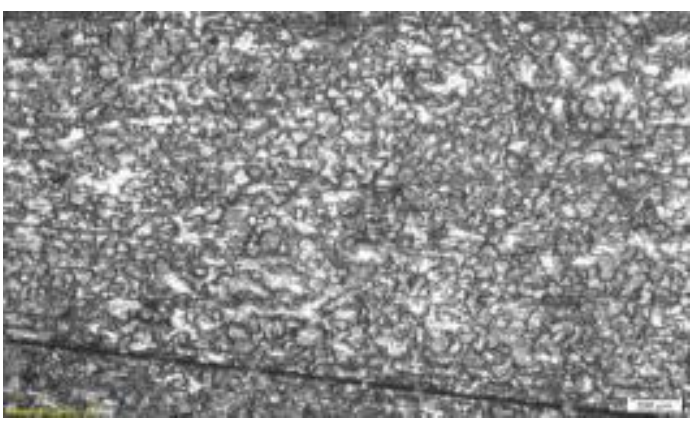

e. Perendaman dengan inhibitor $9 \%$

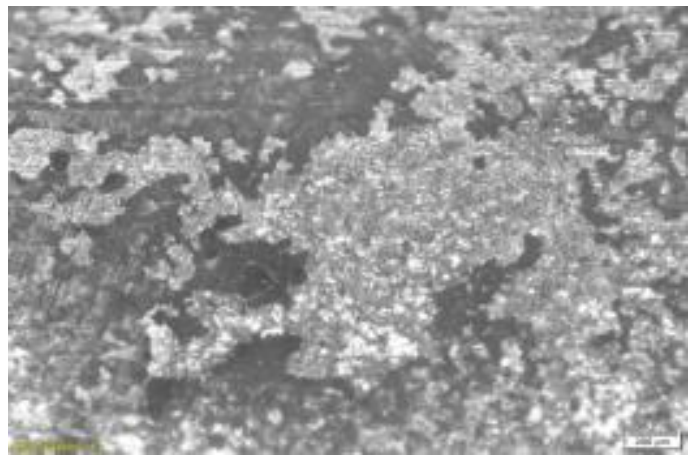

b. Perendaman dengan inhibitor $0 \%$

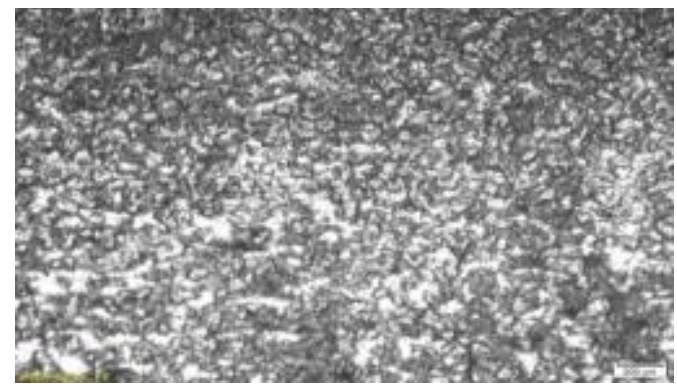

d. Perendaman dengan inhibitor $7 \%$

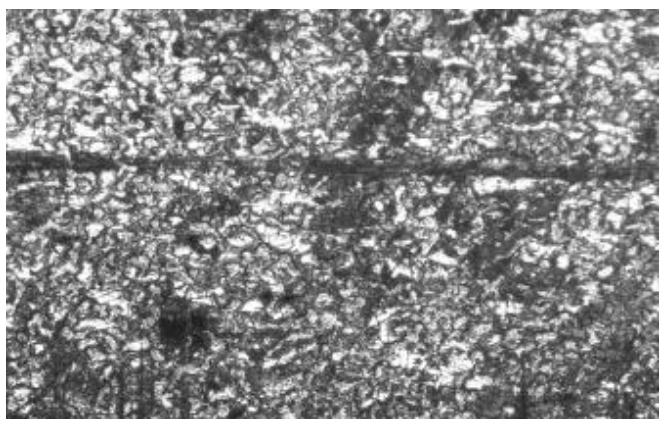

f. Perendaman dengan inhibitor $11 \%$

Gambar 10. Hasil Pengujian Metalografi Perendaman Spesimen tanpa menggunakan Pompa 


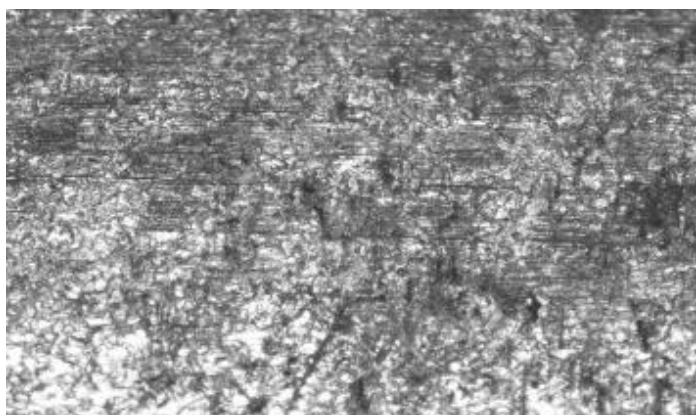

a. Sebelum perendaman

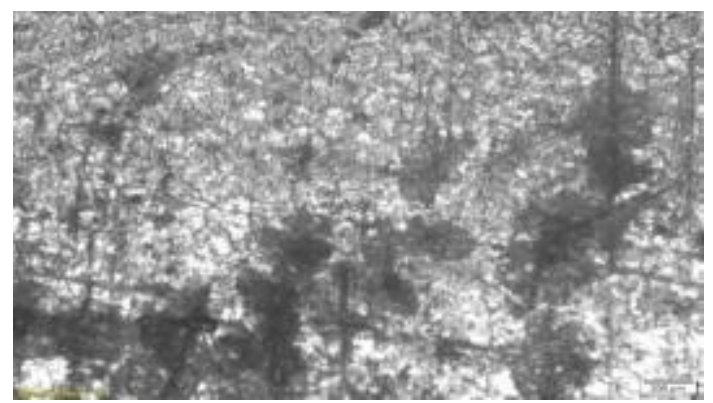

c. Perendaman dengan inhibitor $5 \%$

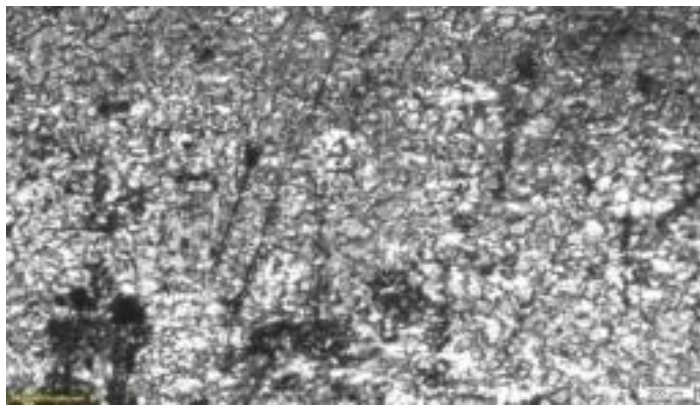

e. Perendaman dengan inhibitor $9 \%$

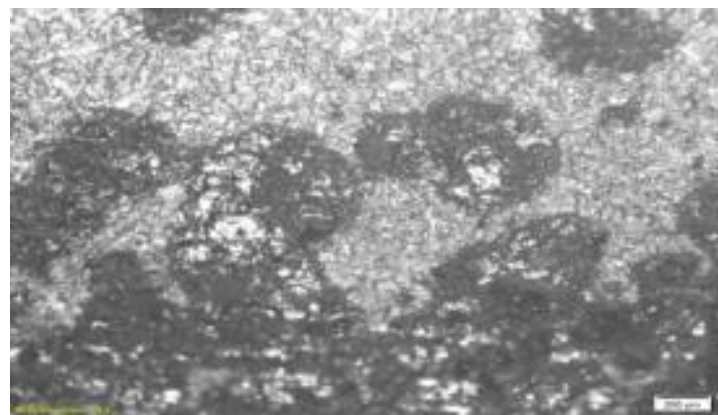

b. Perendaman tanpa inhibitor

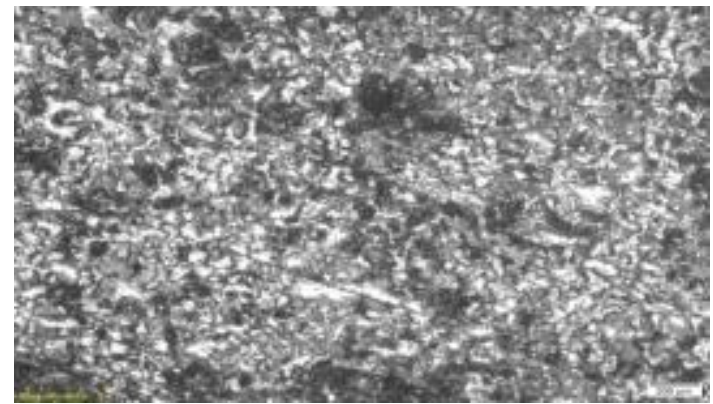

d. Perendaman dengan inhibitor $7 \%$

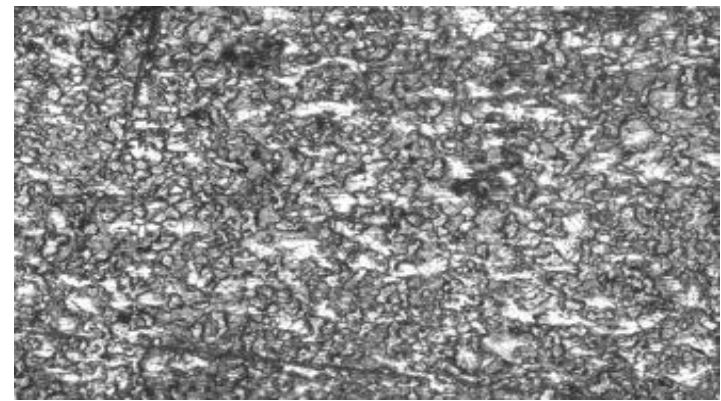

f. Perendaman dengan inhibitor $11 \%$

Gambar 11. Hasil Pengujian Metalografi Perendaman Spesimen dengan menggunakan Pompa

\section{KESIMPULAN}

Dari hasil penelitian korosi pada pipa jenis galvanis maka dapat diambil kesimpulan. Yang pertama, air gambut menyebabkan terjadinya korosi pada pipa galvanis dengan laju korosi sebesar $0,031 \mathrm{~mm} / \mathrm{y}$ pada perendaman tanpa pompa dan $0,038 \mathrm{~mm} / \mathrm{y}$ pada perendaman menggunakan pompa. Pada perendaman menggunakan pompa laju korosinya lebih besar hal ini dikarenakan fluida yang bergerak dapat mempercepat proses korosi.

Kemudian penambahan inhibitor ekstrak daun jambu biji dapat menurunkan laju korosi dari $0,031 \mathrm{~mm} / \mathrm{y}$ menjadi $0,018 \mathrm{~mm} / \mathrm{y}$ pada perendaman tanpa pompa dan pada perendaman menggunakan pompa laju korosinya menurun dari $0,038 \mathrm{~mm} / \mathrm{y}$ menjadi $0,019 \mathrm{~mm} / \mathrm{y}$ karena ekstrak daun jambu biji dapat bereaksi dan membentuk lapisan tipis pada permukaan logam yang berfungsi menghambat serangan korosi pada logam.

Pada perendaman tanpa menggunakan pompa nilai efisiensi tertinggi didapat pada konsentrasi inhibitor 9\% yaitu nilai efisiensinya sebesar $44 \%$, dan pada perendaman dengan menggunakan pompa nilai efisiensi tertingginya didapat pada konsentrasi inhibitor $11 \%$ yaitu nilai efisiensinya sebesar 49\%. Pada perendaman tanpa pompa dengan konsentrasi inhibitor $11 \%$ efisiensi inhibitor kembali turun karena pada konsentrasi 
inhibitor 9\% merupakan konsentrasi optimum sehingga pada konsentrasi $11 \%$ tidak lagi meningkatkan efisiensi dari inhibitor sehingga efisiensi inhibitor cenderung konstan bahkan turun.

Hasil penelitian ini diharapkan mampu membantu penelitian-penelitian selanjutnya mengenai konsentrasi ekstrak inhibitor daun jambu biji. Hasil penelitian ini juga diharap mampu membantu industri-industri dalam menangani permasalahan korosi yang sering dijumpai.

Adapun untuk pengembangan penelitian ke depannya, variasi pada konsentrasi inhibitor, metode penghitungan dan jenis inhibitor dapat diperluas. Hal ini diharapkan mampu memberi hasil atau temuan yang lebih signifikan.

\section{DAFTAR PUSTAKA}

Ali, F., Saputri, D., \& Nugroho, R. F. (2014).

Pengaruh Waktu Perendaman Dan

Konsentrasi Ekstrak Daun Jambu Biji (Psidiun Guajava,linn) Sebagai Inhibitor Terhadap Laju Korosi Baja SS 304 Dalam Larutan Garam Dan Asam. Jurnal Teknik Kimia Universitas Sriwijaya, 20(1), 2837.

Amalia, I. (2016). Pengaruh Variasi Konsentrasi Ekstrak Daun Jambu Biji (Psidium Guajava) dan Daun Cengkeh (Syizigum aromaticum) Sebagai Inhibitor Organik Pada API 5L GRADE B Dilingkungan $\mathrm{NaCl} 3,5 \% \mathrm{pH} 4$.

Anggriawan, A., Saputra, E., \& Olivia, M. (2015). Penyisihan Kadar Logam Fe dan Mn Pada Air Gambut DenganPemanfaatan Geopolimer Dari Kaolin Sebagai Adsorben. Jom FTEKNIK, 2(1), 1-6.

Anyiam, C. K., Ogbobe, O., Oguzie, E. E., Madufor, I. C., Nwanonenyi, S. C., Onuegbu, G. C., Obasi, H. C., \& Chidiebere, M. A. (2020). Corrosion inhibition of galvanized steel in hydrochloric acid medium by a physically modified starch. SN Applied Sciences, 2(4). https://doi.org/10.1007/s42452-0202322-2

Cholil, M. N., Ramadhan, D., \& Maulidia, Y. (2018). Inhibisi Korosi Pada Baja Lunak Dalam Media Air Gambut Dengan Metode Elektroplating. ELKHA, 10(2). https://doi.org/10.26418/elkha.v10i2.262 02

Irianty, R. S., \& Khairat. (2013). Ekstrak Daun Pepaya sebagai Inhibitor Korosi pada Baja AISI 4140 dalam Medium Air Laut. Jurnal Ilmiah Sains Terapan, 4(2).

\section{Mulyati, B. (2020). TANIN DAPAT DIMANFAATKAN SEBAGAI INHIBITOR KOROSI. Jurnal Industri Elektro Dan Penerbangan (INDEPT), $8(1)$.}

Tambun, R., Limbong, H. P., Nababan, P., \& Sitorus, N. (2015). Kemampuan Daun Jambu Biji sebagai Inhibitor Korosi Besi pada Medium Asam Klorida. Jurnal Kimia Dan Kemasan, 37(2). https://doi.org/10.24817/jkk.v37i2.1815

Wahyuni, T., \& Ab, S. (2014). PEMANFAATAN TANIN EKSTRAK DAUN JAMBU BIJI TERHADAP LAJU KOROSI BESI DALAM LARUTAN $\mathrm{NaCl}$ 3\%. Jurnal Konversi, 3(1), 45-52. 